Supporting Information

\title{
Synthesis of the Lipophilic Amine Tail of Abediterol Enabled by Multiphase Flow Transformations
}

Jorge García-Lacuna, ${ }^{\dagger}$ Tobias Flei $\beta,{ }^{\dagger}, \star$ Rachel Munday,${ }^{\S}$ Kevin Leslie,${ }^{\S}$ Anne O’Kearney-McMullan, ${ }^{\S}$ Christopher A. Hone, ${ }^{*},+, \neq$ and C. Oliver Kappe ${ }^{*,+, \neq}$

${ }^{\dagger}$ Institute of Chemistry, University of Graz, NAWI Graz, Heinrichstrasse 28, A-8010 Graz, Austria

¥ Center for Continuous Flow Synthesis and Processing (CCFLOW), Research Center Pharmaceutical Engineering GmbH (RCPE), Inffeldgasse 13, 8010 Graz, Austria

$\S$ Chemical Development, Pharmaceutical Technology \& Development, Operations, AstraZeneca, Macclesfield, United Kingdom

\section{Contents}

1.1 O-Alkylation and Hydroformylation Telescoped Flow Setup...........................................2

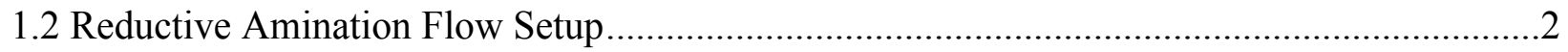

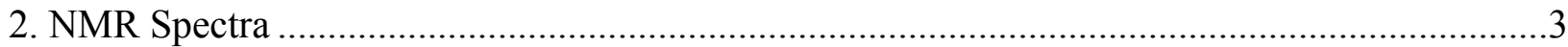




\subsection{O-Alkylation and Hydroformylation Telescoped Flow Setup}

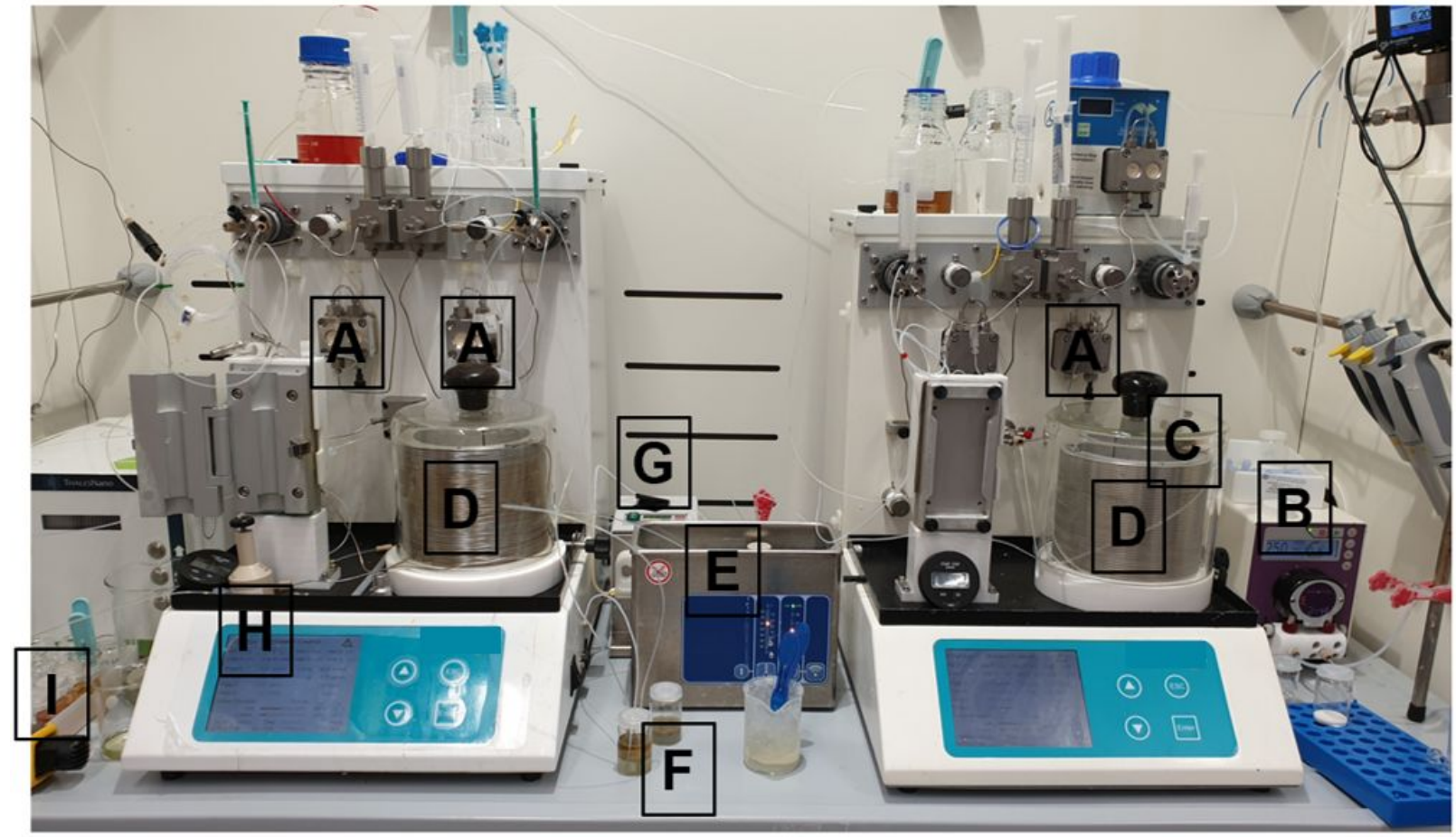

Figure S1. Labeled image for the $O$-alkylation and hydroformylation flow setup. A $=$ HPLC pump, $\mathrm{B}=$ peristaltic pump, $\mathrm{C}=\mathrm{Y}$-mixer, $\mathrm{D}=$ coil reactor, $\mathrm{E}=\mathrm{BPR}$ placed within an ultrasound bath, $\mathrm{F}$ = gravity separator, $\mathrm{G}=$ peristaltic pump, $\mathrm{H}=\mathrm{BPR}, \mathrm{I}=\mathrm{CO}$ monitor.

\subsection{Reductive Amination Flow Setup}

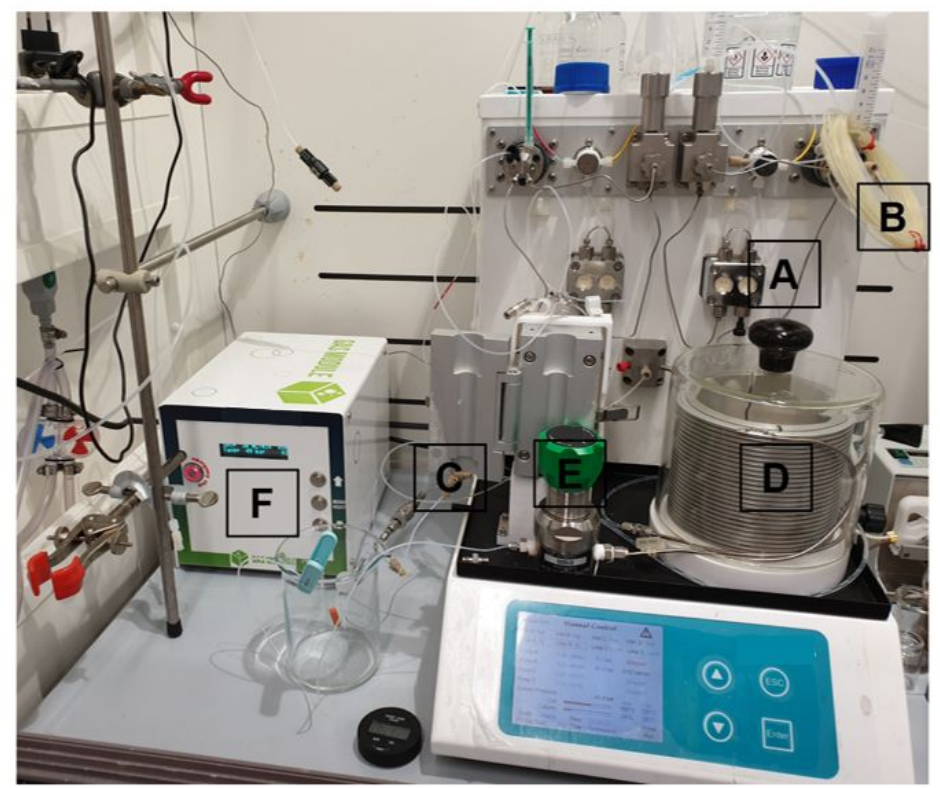

Figure S2. Labelled image for the reductive amination flow setup. A $=$ HPLC pump, B = sample loop/injector valve, $\mathrm{C}=\mathrm{Y}$-mixer, $\mathrm{D}=$ coil reactor, $\mathrm{E}=\mathrm{BPR}, \mathrm{F}=$ mass flow controller. 


\section{NMR Spectra}

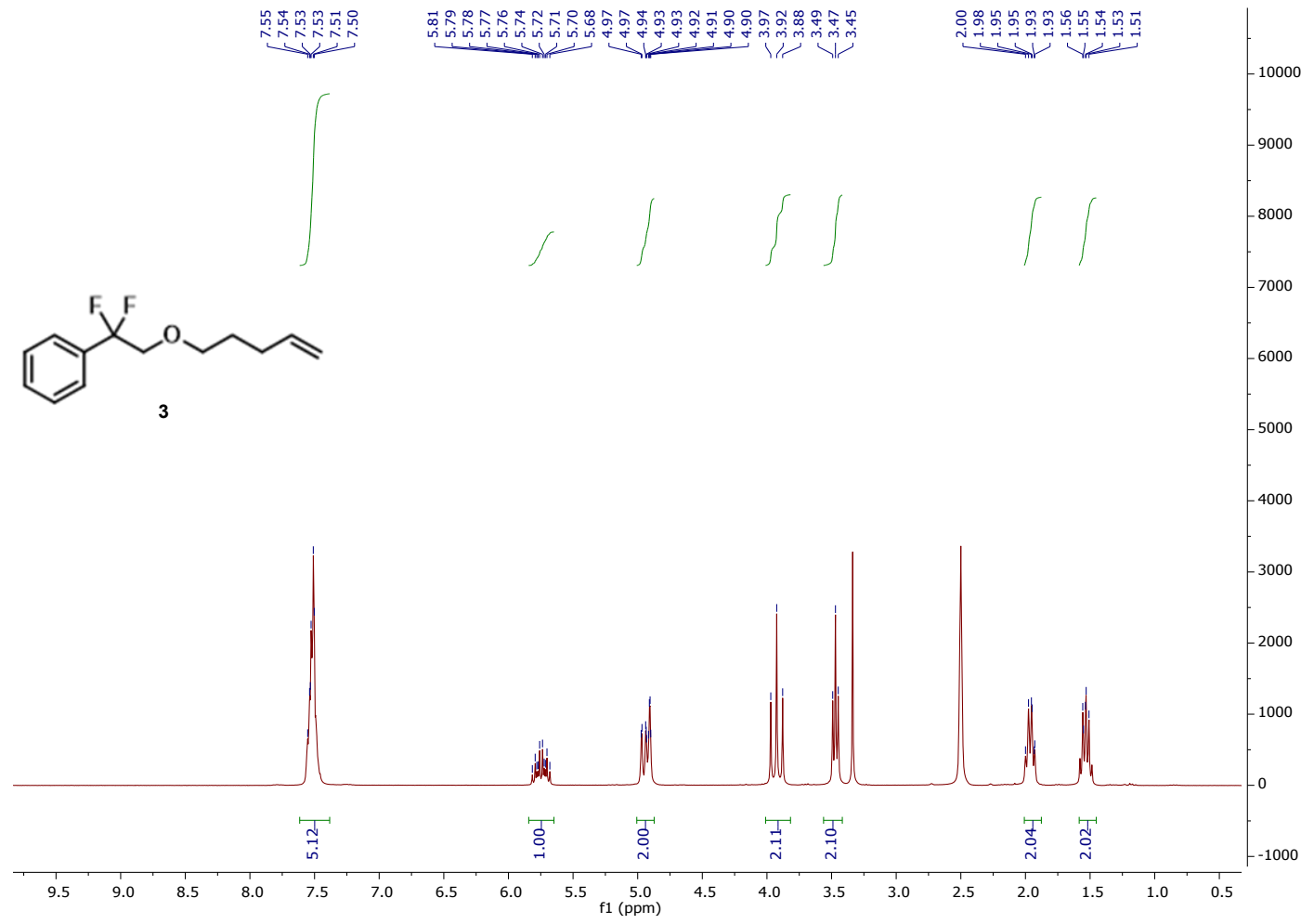

Figure S3. ${ }^{1} \mathrm{H}$ NMR spectrum of (1,1-Difluoro-2-(pent-4-en-1-yloxy)ethyl)benzene (3) in DMSO-d ${ }_{6}$.

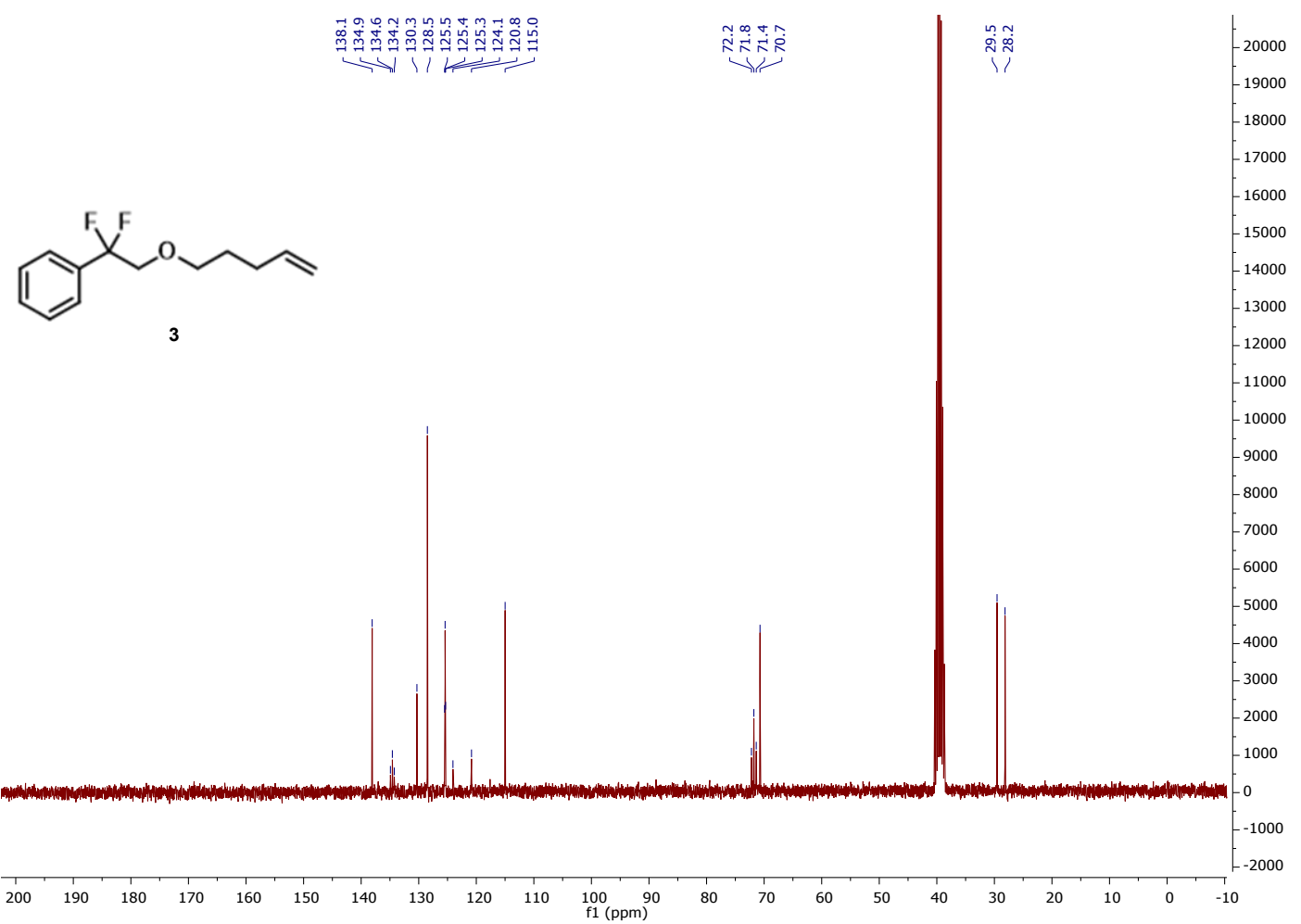

Figure S4. ${ }^{13} \mathrm{C}$ NMR spectrum of (1,1-Difluoro-2-(pent-4-en-1-yloxy)ethyl)benzene (3) in DMSO-d 6 . 


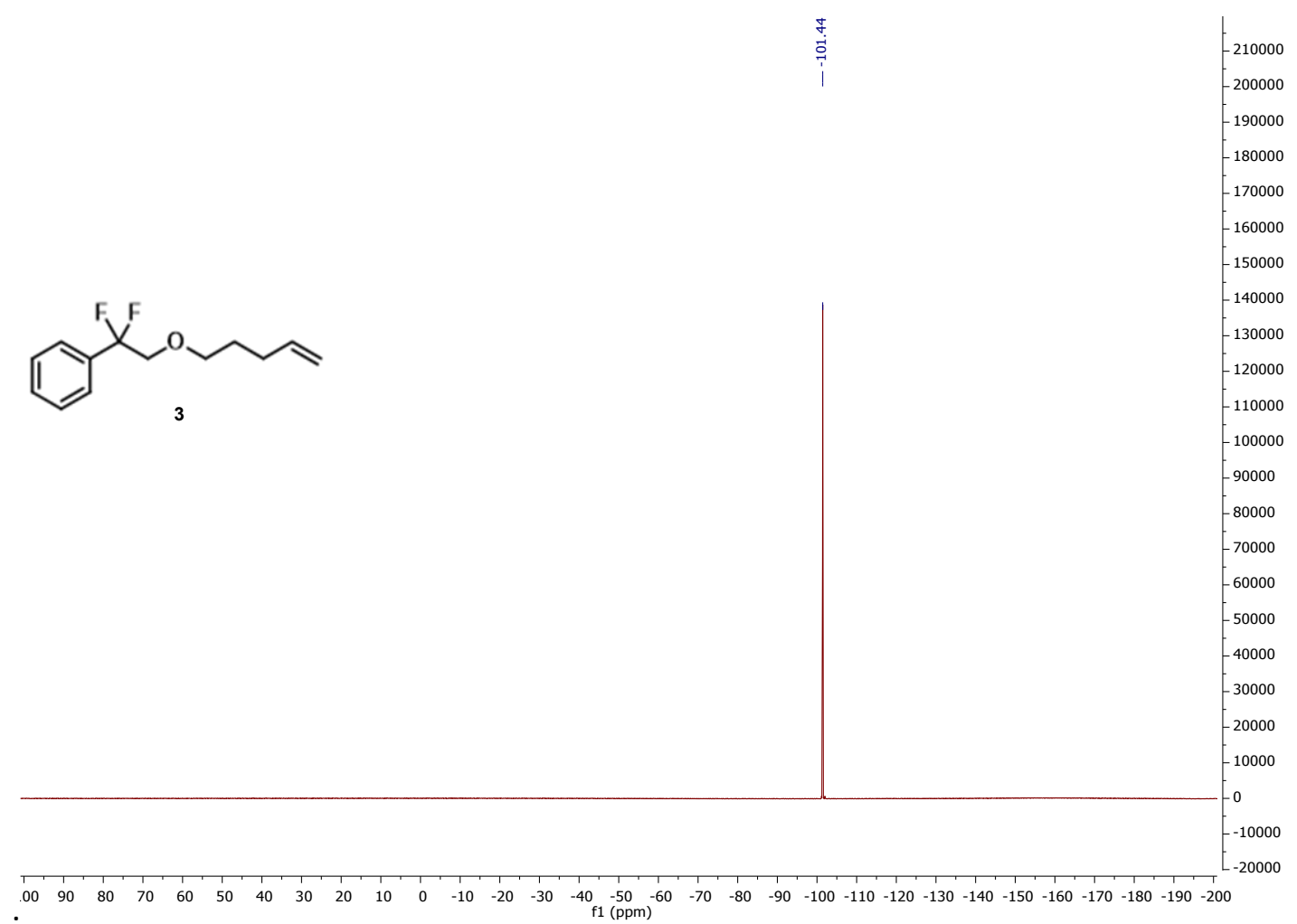

Figure S5. ${ }^{19} \mathrm{~F}$ NMR spectrum of (1,1-Difluoro-2-(pent-4-en-1-yloxy)ethyl)benzene (3) in DMSO-d $\mathrm{d}_{6}$.

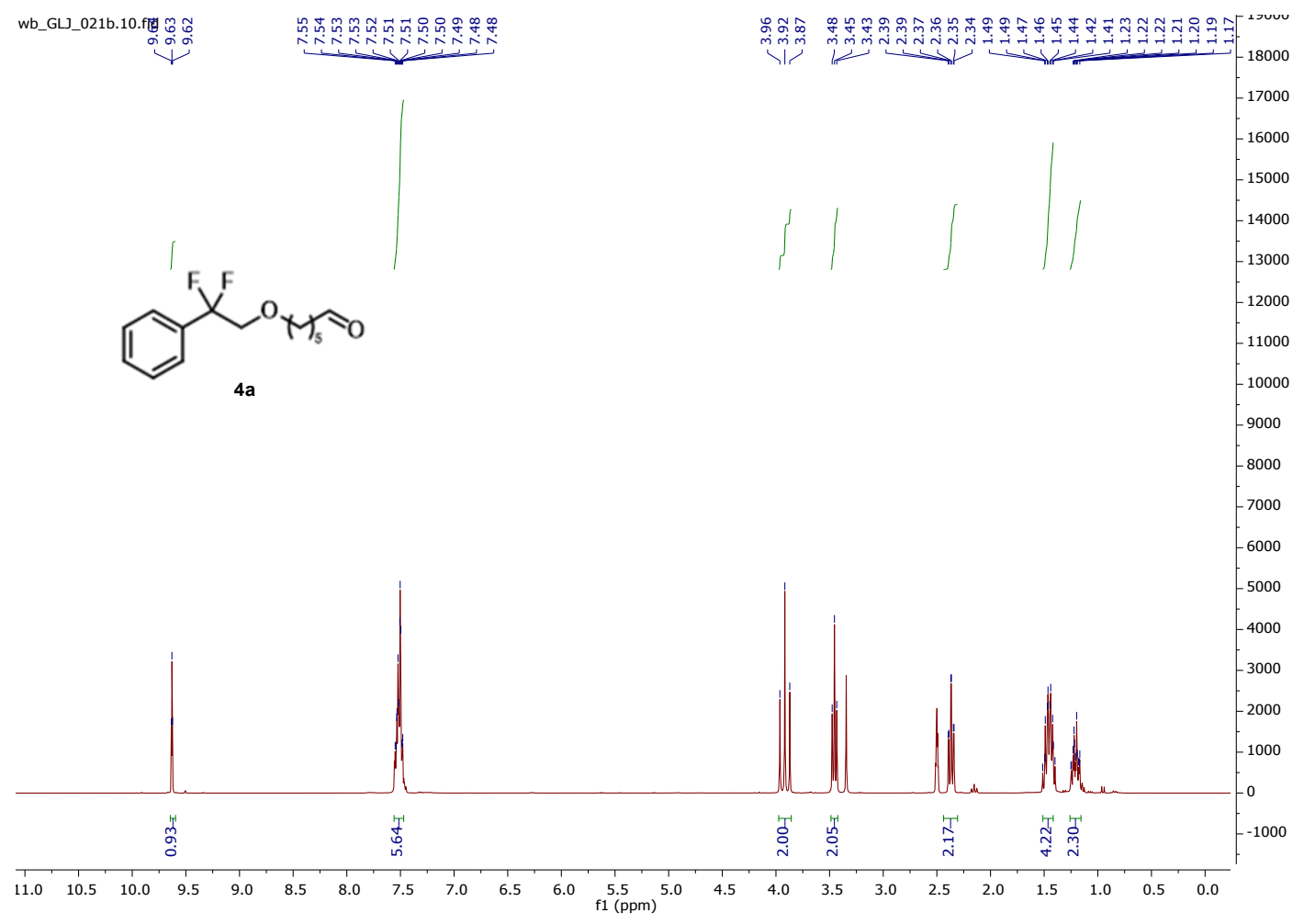

Figure S6. ${ }^{1} \mathrm{H}$ NMR spectrum of 6-(2,2-Difluoro-2-phenylethoxy)hexanal (4a) in DMSO-d 6 . 


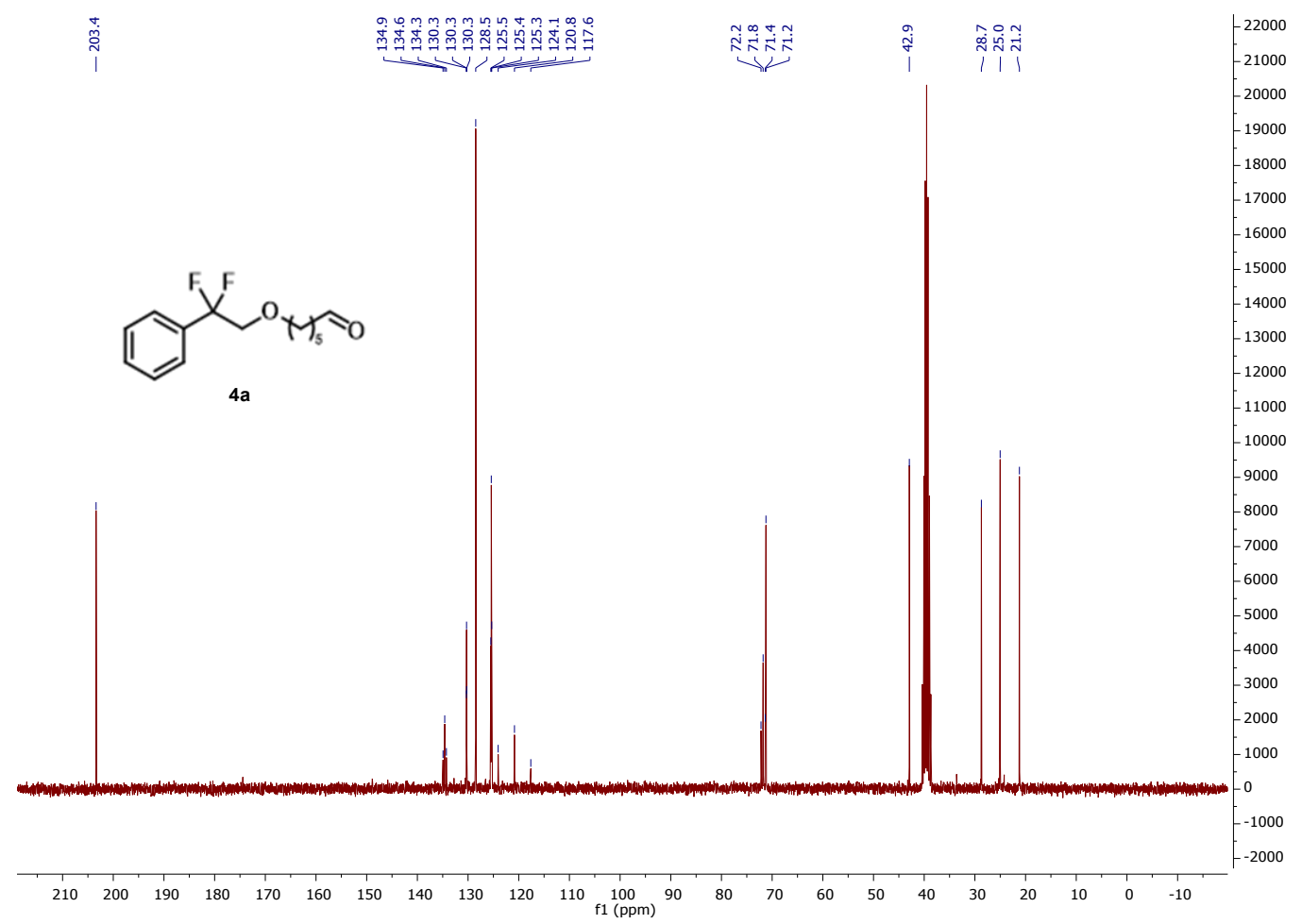

Figure S7. ${ }^{13} \mathrm{C}$ NMR spectrum of 6-(2,2-Difluoro-2-phenylethoxy)hexanal (4a) in DMSO-d ${ }_{6}$.

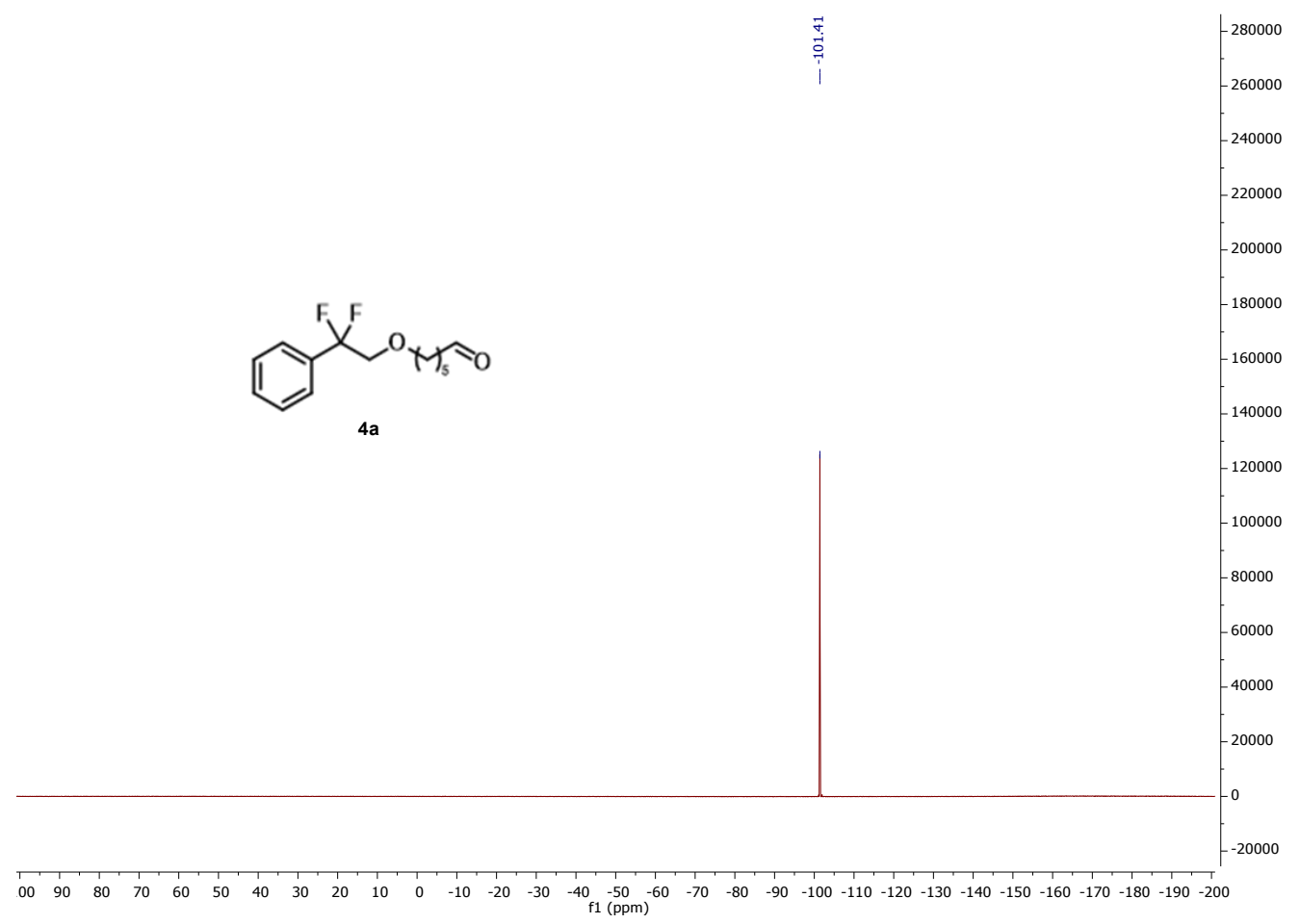

Figure S8. ${ }^{19} \mathrm{~F}$ NMR spectrum of 6-(2,2-Difluoro-2-phenylethoxy)hexanal (4a) in DMSO-d 6 . 


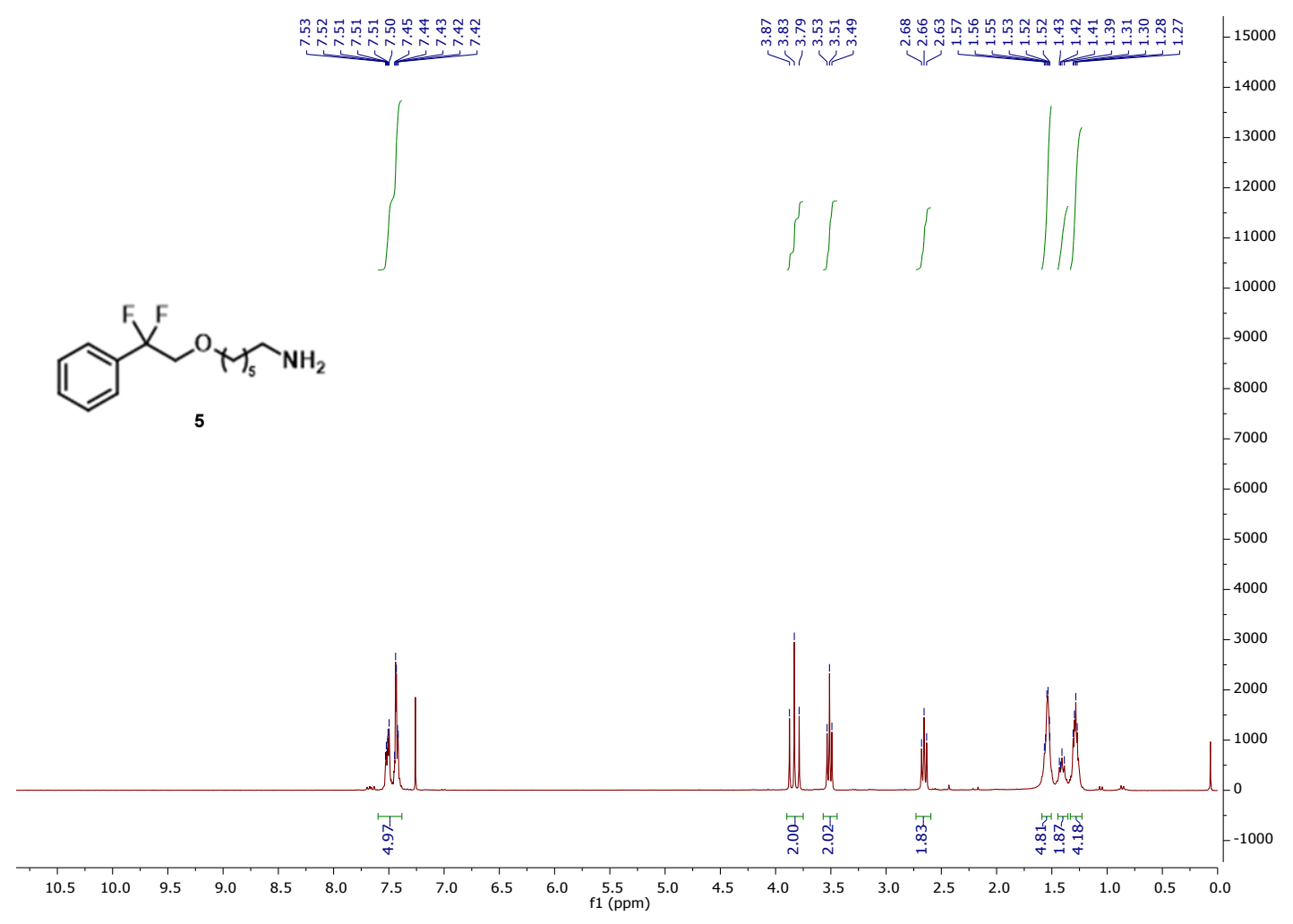

Figure S9. ${ }^{1} \mathrm{H}$ NMR spectrum of 6-(2,2-difluoro-2-phenylethoxy)hexan-1-amine (5) in $\mathrm{CDCl}_{3}$.

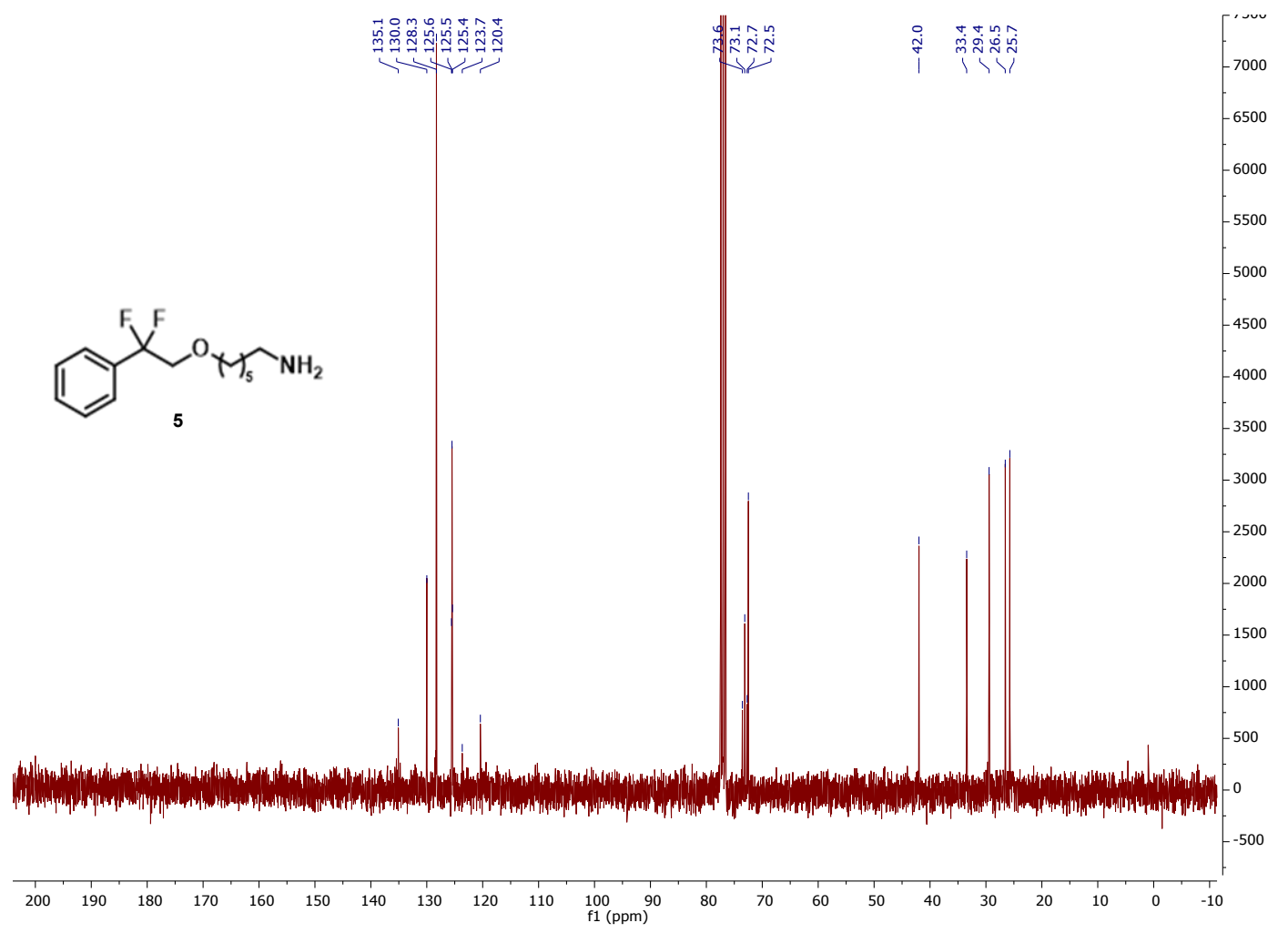

Figure S10. ${ }^{13} \mathrm{C}$ NMR spectrum of 6-(2,2-difluoro-2-phenylethoxy)hexan-1-amine (5) in $\mathrm{CDCl}_{3}$. 


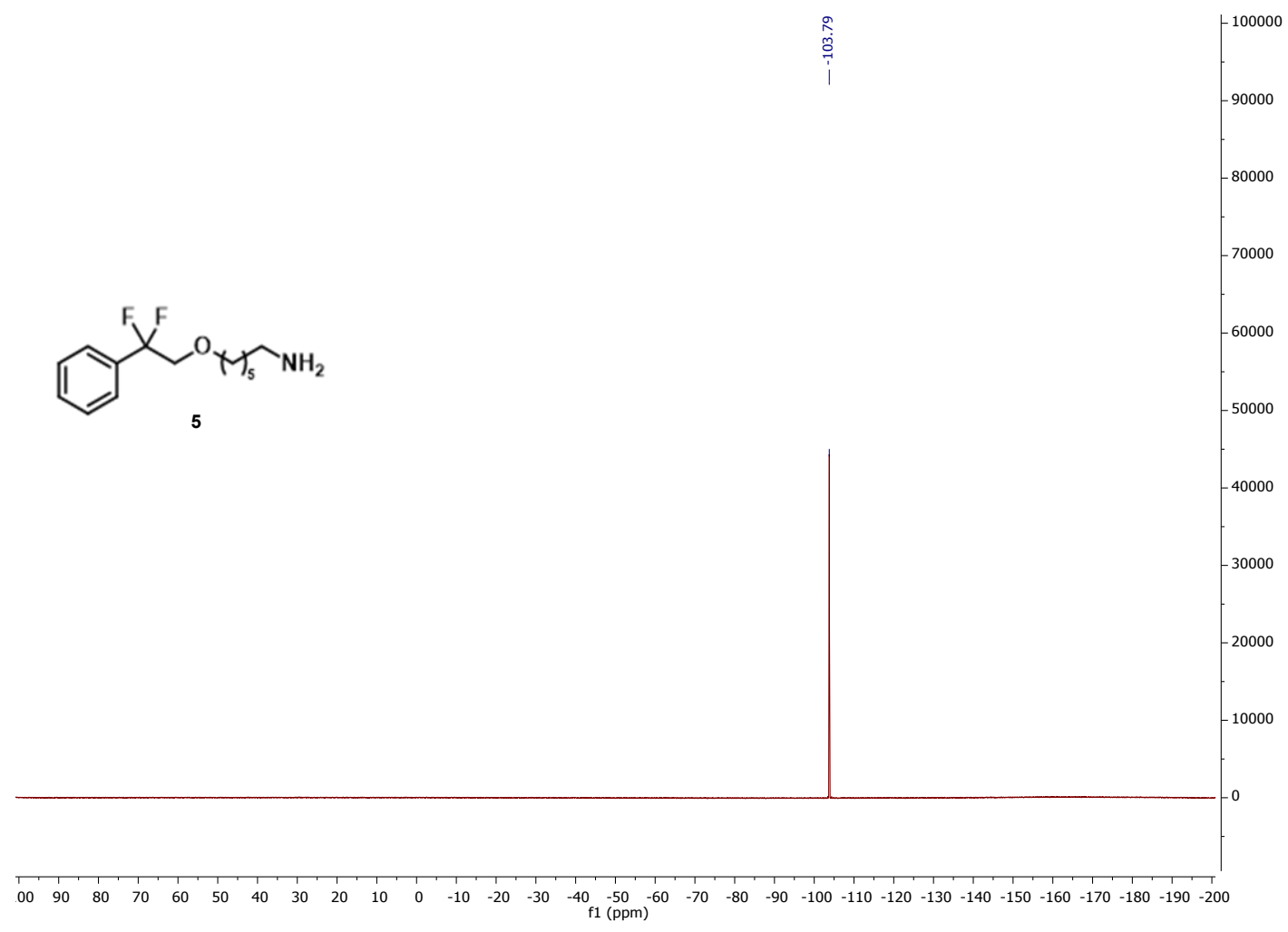

Figure S11. ${ }^{19} \mathrm{~F}$ NMR spectrum of 6-(2,2-difluoro-2-phenylethoxy)hexan-1-amine (5) in $\mathrm{CDCl}_{3}$. 